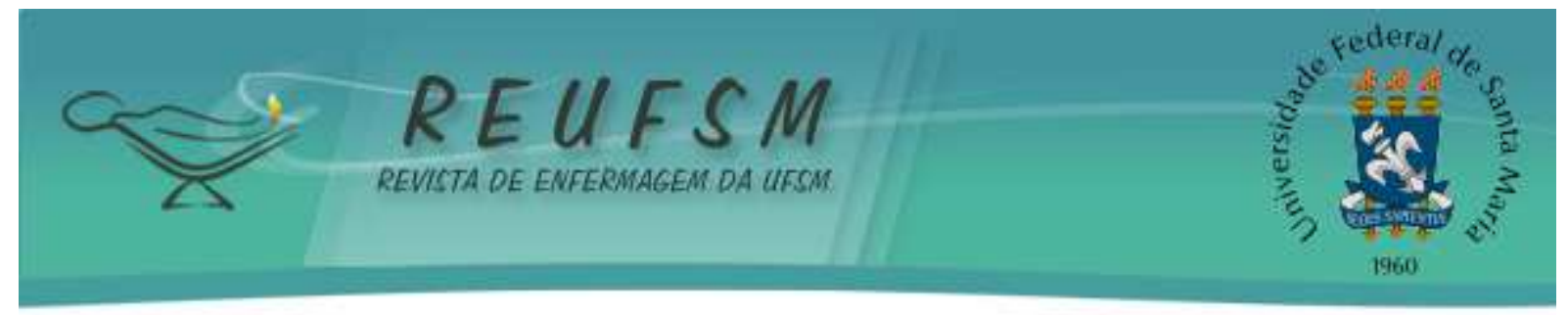

\title{
MUNDO DA DOENÇA MENTAL: PERCEPÇÕES E PERSPECTIVAS NO PROCESSO SAÚDE-DOENÇA
}

WORLD OF MENTAL DISEASE: PERCEPTIONS AND PERSPECTIVE

OF THE HEALTH DISEASE PROCESS

MUNDO DE LA ENFERMEDAD MENTAL: PERCEPCIONES Y PERSPECTIVAS

EN EL PROCESO SALUD ENFERMEDAD

Gabriela Zenatti Ely ${ }^{1}$

Marlene Gomes Terra ${ }^{2}$

Adão Ademir da Silva ${ }^{3}$

Fernanda Franceschi de Freitas 4

Cristina Thum ${ }^{5}$

Éder Luis Arboit ${ }^{6}$

Doi: $10.5902 / 2179769227371$

RESUMO: Objetivo: desvelar a percepção do ser humano na descoberta do mundo da doença mental e as perspectivas no processo saúde-doença. Método: estudo fenomenológico, desenvolvido com 10 adultos em tratamento em uma unidade de internação psiquiátrica, no hospital público de um município do sul do Brasil. A produção de dados ocorreu por meio da entrevista fenomenológica, no período de janeiro a março de 2014. Utilizou-se a fenomenologia-hermenêutica de Paul Ricoeur e para a compreensão dos discursos, o referencial teórico-filosófico de Maurice Merleau-Ponty. Resultados: o diagnóstico da doença mental permeia a vivência pela generalidade e hábito, os quais, expõem os paradigmas. Contudo, quando se mostra como corpo próprio, emerge a singularidade enquanto ser no mundo para as percepções do processo saúde-doença. Conclusão: para tanto, faz-se necessário desvelar as reais necessidades do ser humano, a fim de tecer redes de significações diante do processo saúde-doença e perspectivas terapêutica.

Descritores: Saúde mental; Estresse psicológico; Percepção; Hospitalização

\footnotetext{
${ }^{1}$ Enfermeira. Mestre pelo programa de pós-graduação em Enfermagem da Universidade Federal de Santa Maria (PPGENF UFSM). Professora no Curso de Enfermagem da Universidade de Cruz Alta. Santa Maria, Rio Grande do Sul, Brasil. E-mail: gabii_ely@yahoo.com.br

${ }^{2}$ Enfermeira. Pós-doutorado em Enfermagem pela Universidade Federal do Rio Grande do Sul - UFRGS. Professora do Programa de Pós-Graduação em Enfermagem (PPGEnf). Líder do Grupo de Pesquisa "Cuidado em Saúde Mental e Formação em Saúde" (FORESM). Santa Maria, Rio Grande do Sul, Brasil. E-mail: martesm@hotmail.com.br

${ }^{3}$ Psicólogo e Enfermeiro. Doutor em Psicologia Social pela Pontifícia Universidade Católica do Rio Grande do Sul. Enfermeiro no Hospital Universitário de Santa Maria (HUSM). Santa Maria, Rio Grande do Sul, Brasil. Email: aaspsiadao@gmail.com

${ }^{4}$ Enfermeira. Mestre pelo programa de pós-graduação em Enfermagem da Universidade Federal de Santa Maria (PPGENF UFSM). Enfermeira no Hospital Universitário de Santa Maria (HUSM). Santa Maria, Rio Grande do Sul, Brasil. E-mail: fe_franceschi@yahoo.com.br

${ }^{5}$ Enfermeira. Mestre em Enfermagem e Saúde FURG. Professora no Curso de Enfermagem da Universidade de Cruz Alta. Cruz Alta, Rio Grande do Sul, Brasil. E-mail: crthum@Unicruz.edu.br

${ }^{6}$ Enfermeiro. Mestre pelo programa de pós-graduação em Enfermagem da Universidade Federal de Santa Maria (PPGENF UFSM). Docente no Curso de Enfermagem da Universidade de Cruz Alta. Palmeira das Missões, Rio Grande do Sul, Brasil. E-mail: earboit@unicruz.edu.br
} 


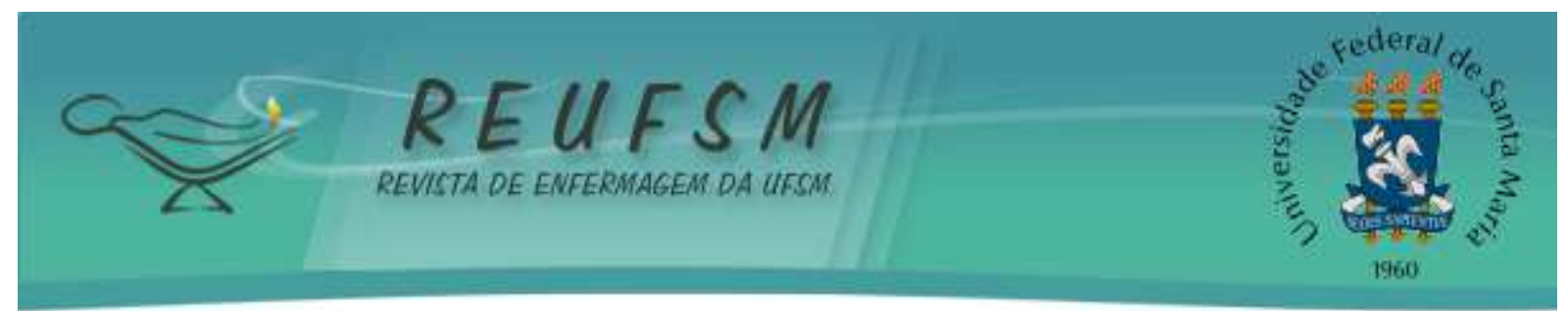

ABSTRACT: Aim: to unveil the perception of the human being in the discovery of the world of mental illness and the prospects in the health disease process. Method: phenomenological study developed with 10 adults undergoing treatment in a psychiatric inpatient unit of a public hospital in a municipality in the south of Brazil. The production of data occurred through the phenomenological interview from January to March, 2014. Paul-Ricoeur's phenomenology-hermeneutics and Maurice Merleau-Ponty's theoretical-philosophical reference were used to understand the discourses. Results: the diagnosis of mental illness permeates the experience by generality and habit, which expose the historical paradigms. However, when it is shown as a body itself, the singularity emerges as a being in the world for the perceptions of the disease health process. Conclusion: to do so, it is necessary to unveil the real needs of the human being, in order to weave networks of meanings before the health disease and therapeutic perspectives processes.

Descriptors: Mental health; Psychological stress; Perception; Hospitalization

RESUMEN: Objetivo: revelar la percepción del ser humano en el descubrimiento del mundo de la enfermedad mental y las perspectivas en el proceso salud enfermedad. Método: estudio de perspectiva fenomenológica, desarrollado con 10 adultos en tratamiento en una unidad de internación psiquiátrica, de un hospital público de una ciudad del sur de Brasil. La recolección de datos ocurrió por medio de entrevista fenomenológica, desarrollada en entre enero y marzo de 2014. Para el análisis se utilizó la fenomenología hermenéutica, de Paul Ricoeur, y para la comprensión de los discursos el referencial teórico filosófico de Maurice Merleau-Ponty. Resultados: el diagnóstico de la enfermedad mental está relacionada con la vivencia por la generalización y el hábito, los cuales evidencian los paradigmas. Sin embargo, cuando se expone como cuerpo propio emerge la singularidad del ser en el mundo para las percepciones del proceso salud enfermedad. Conclusión: para tanto es necesario revelar las reales necesidades del ser humano, con el objetivo de tejer redes de significaciones sobre el proceso salud enfermedad y perspectivas terapéuticas.

Descriptores: Salud mental; Estrés psicológico; La percepción; Hospitalización

\section{INTRODUÇÃO}

A compreensão do processo saúde-doença engloba múltiplos fatores de uma sociedade em um determinado contexto histórico. Os determinantes e condicionantes da saúde, a legislação vigente no país, a compreensão da sociedade e o modelo de saúde influenciam as concepções do processo saúde-doença e as intervenções propostas nas políticas públicas de saúde. ${ }^{1}$

Em se tratando da saúde mental, um importante marco foi a Reforma Psiquiátrica ${ }^{2}$ de 2001, a qual prevê o direcionamento do cenário de tratamento do hospital para o território do sujeito, o que inclui dispositivos de cuidado e implicações no compreender o processo saúdedoença. Mostra a necessidade de mudança na forma do gerenciamento do cuidado, que engloba a organização social e todos os serviços da linha de cuidado em saúde mental. Alvitra 


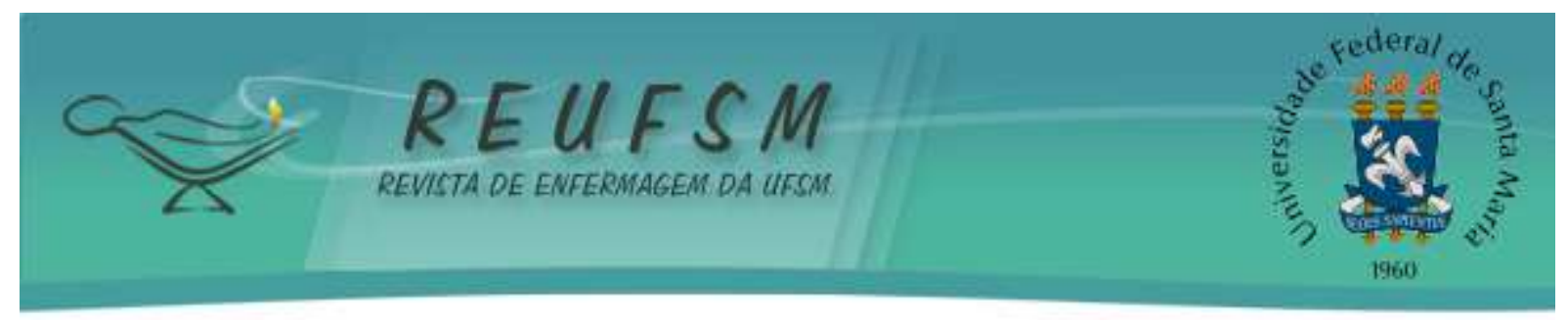

o cuidar sob o enfoque da correponsabilização entre equipes de referências, apoiadores matriciais e ações intersetorias. ${ }^{3-5}$

Para tanto, o movimento social e político da Reforma Psiquiátrica propôs uma mudança de paradigma do modelo hospitalocêntrico para o biopsicossocial. Enfatiza-se, o protagonismo da pessoa que vivencia a doença mental no processo saúde-doença, em ações de corresponsabilidade no tratamento e de promoção de vida. ${ }^{5-6}$ Logo, pesquisas com enfoque fenomenológico proporcionam o pensamento reflexivo no cotidiano, num incessante processo do aprender a aprender. ${ }^{7-8}$

Nessa perspectiva, o cuidar em enfermagem aborda a totalidade do processo baseado no vínculo entre os seres humanos, na educação em saúde, na reflexão crítica do processo, que desperta ações em saúde do sujeito para o autocuidado, em decisões e poder de escolha informada. $\mathrm{O}$ ato de cuidar aproxima o enfermeiro do corpo do outro indivíduo. ${ }^{9-11}$ Portanto, quando a enfermagem intenciona o cuidar, o corpo constitui-se como instrumento de modificações no mundo, pois abriga o próprio mundo do ser humano. ${ }^{9-10}$

Ao realizar a revisão narrativa da produção científica nacional e internacional sobre a temática evidenciou-se lacunas do conhecimento, no que tange a percepção do ser humano sobre o viver com a doença mental com enfoque em Merleau Ponty. As literaturas corroboram para a doença mental centrada em um modelo cartesiano, em detrimento do significado para o ser humano que a vivencia.

Nos estudos nacionais, evidencia-se que há necessidade de uma explicação pontual da causalidade da doença mental, expressa pela descoberta do diagnóstico como marco negativo do contex to social e familiar do paciente. ${ }^{12-16} \mathrm{O}$ sujeito passa a ser a própria doença mental no momento em que manifesta os sintomas clássicos da psiquiatria, (alucinações, delírios, comportamento bizarro) do estereótipo do louco social e do poder do diagnóstico. Reflete a doença no estigma, culpa e frustração social, o que o torna dependente do outro e inútil para o trabalho. Além disso, a descoberta da doença mental significa o rompimento das convivências e significados do cotidiano e uma possível perda diante do sentido das experiências de vida, ${ }^{14}$ as quais podem acarretar, por vezes, em suicídio. ${ }^{15-16}$ Não há menção do sujeito diante da compreensão desse fenômeno, sendo que tratamento psiquiátrico se encontra marcado pela normalização e punição. ${ }^{16-19}$ 


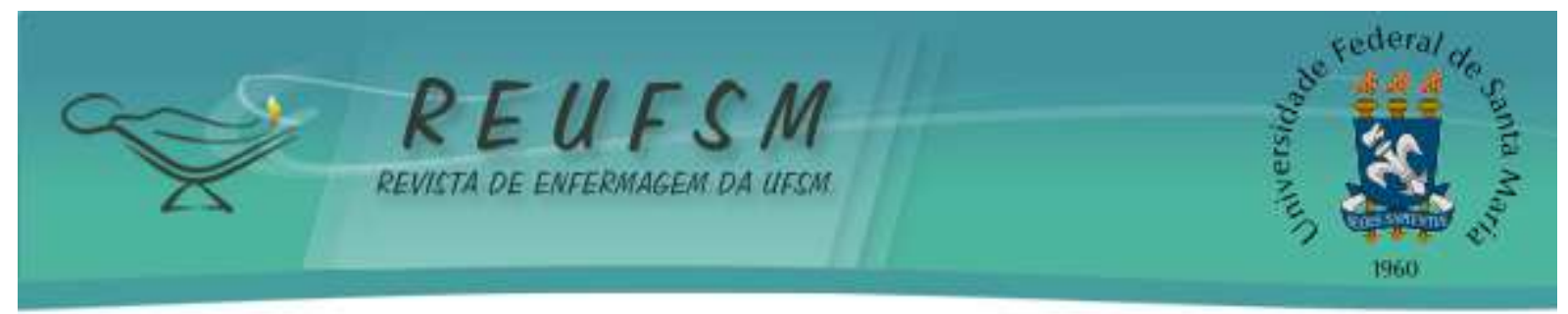

Já em estudos internacionais, o hospital foi referido como um serviço que retirava a liberdade e a percepção de despersonalização dos pacientes. Foram identificadas duas formas de enfrentamento dessa situação: a primeira de aceitação passiva, o que desencadeava menos atitudes coercitivas e punitivas da equipe; e, a segunda, de evitação, sendo um exemplo, o comportamento de dormir ou ficar no leito a maior parte do tempo. ${ }^{17-19}$

No intuito de explorar o mundo do sujeito que vivencia a doença mental, estabeleceuse a pergunta norteadora: como o ser humano internado em unidade psiquiátrica percebe o viver com doença mental? E como objetivo desse artigo a exploração do tema de um estudo fenomenológico: desvelar a percepção do ser humano na descoberta do mundo da doença mental e as perspectivas no processo saúde-doença.

\section{MÉTODO}

Trata-se de um estudo fenomenológico, a partir do referencial metodológico do filósofo francês Paul Ricoeur e do referencial teórico-filosófico de Maurice Merleau-Ponty, os quais propiciam a compreensão do cotidiano de vivências. ${ }^{7-8,20}$ A fenomenologia busca descrever os fenômenos que se mostram e se expressam pelo discurso oral do ser humano.

Essa abordagem almeja captar os sentidos das vivências, na coexistência com os outros, por suas ações e relações que são históricas, sociais e políticas, nas manifestações corporais de quem a vivencia. ${ }^{7-8,11}$ A experiência encarnada ao comunicar-se com o mundo, no horizonte do vivido, configura uma unidade indivisa e uma atividade expressiva. Sendo assim, o corpo se constitui o próprio ponto de vista do sujeito sobre o mundo, a fonte dos sentidos das coisas no mundo e cria significações. ${ }^{7-9}$

A pesquisa estabeleceu como cenário de coleta de dados um hospital público localizado em um município no sul do Brasil, que presta assistência de média e alta complexidade atendendo, exclusivamente, aos usuários do Sistema Único de Saúde (SUS). Os participantes foram pessoas adultas, internadas em uma unidade de internação psiquiátrica, que no momento da coleta de dados, voluntariamente assinaram o Termo de Consentimento Livre e Esclarecido (TCLE) para participarem da pesquisa. Nessa unidade, o perfil de pacientes compreende quadros agudos da doença psiquiátrica. Os critérios de inclusão dos participantes perpassaram por pessoas adultas (faixa etária de 18 a 59 anos), de ambos os sexos. E, como critérios de exclusão, adultos com limitações cognitivas, as quais se referem a 


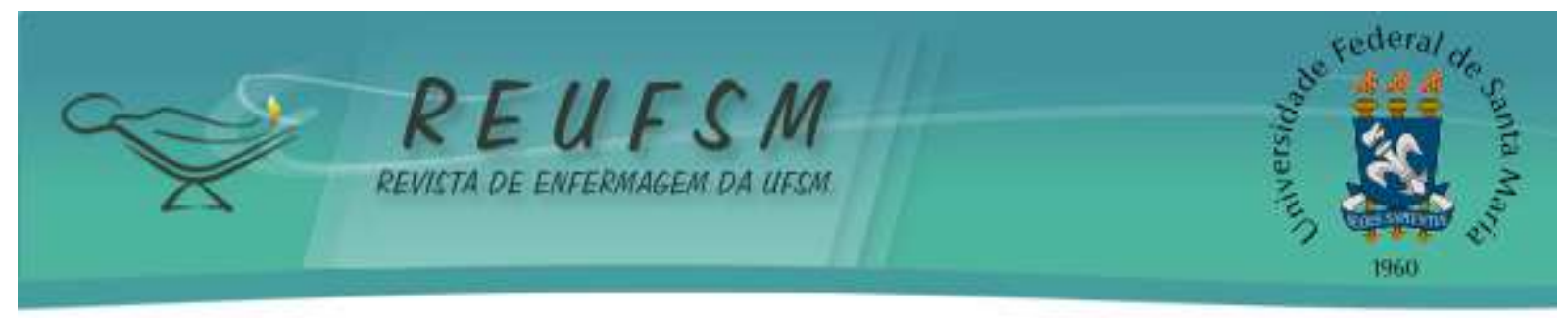

quadros psicóticos agudos, deterioração pelo curso da doença ou efeitos sedativos de medicações, e/ou com sequelas neurológicas incapacitantes, no momento, que restringissem a sua participação no estudo. A avaliação prévia dos participantes foi realizada pela equipe local de saúde, compreendida pelo enfermeiro de plantão e o respectivo residente médico, responsável por cada paciente.

Utilizou-se a entrevista fenomenológica, pois busca acessar o fenômeno interrogado pela compreensão do vivido do ser humano, a partir do "encontro social". Esse possui características especiais como a empatia e a intersubjetividade, mediante mútua percepção entre os envolvidos na entrevista. ${ }^{21}$ Não há um padrão para sua realização. Contudo, o pesquisador necessita ver e observar com a preocupação de não induzir respostas; perceber e compreender a linguagem do outro como veículo de significações. ${ }^{21-22}$

As entrevistas foram realizadas no período de janeiro a março de 2014, individualmente, em uma sala cedida pelos profissionais da unidade de internação, a qual oportunizava privacidade para os diálogos e para as gravações em áudio MP3. Também, foi utilizado um diário de campo, o qual permitiu registrar o essencial do momento da entrevista, tendo em vista a percepção do pesquisador relacionada a expressão corporal do participante. A fim de resguardar o anonimato, foram identificadas pela letra ' $\mathrm{H}$ ' inicial da palavra "Homem" seguidas de algarismos arábicos, conforme a ordem crescente de realização das entrevistas (H1 a H10). A escolha por esse codinome advém da terceira fase metodológica, na qual encontra-se a metáfora, sendo expressa pelo Homem no mar. Refere-se à descrição dos participantes da pesquisa na perspectiva do ser humano (homem e mulher) de acordo com a crônica intitulada Homem no mar. ${ }^{23}$ Reflete o mostrar-se e esconder-se na perspectiva do ser humano nas ondas e o movimento de consciência de si em um mundo inacabado. Sendo assim, a entrevista teve a seguinte questão: como é para você ter uma doença mental?

O número de participantes deste estudo não foi predeterminado, pois a coleta e a análise ocorrem concomitantemente até que as informações obtidas evidenciassem o fenômeno de pesquisa por meio dos discursos. Foram realizadas 10 entrevistas, sendo a mais breve de três minutos e 44 segundos e a mais extensa com 69 minutos e 35 segundos. Contudo, enfatiza-se que o tempo em fenomenologia não decorre da demarcação cronológica. ${ }^{7-8}$

Para compreender e interpretar os discursos, optou-se pela fenomenologiahermenêutica do filósofo francês Paul Ricoeur. ${ }^{20}$ Para o leitor compreender o sentido do texto, 


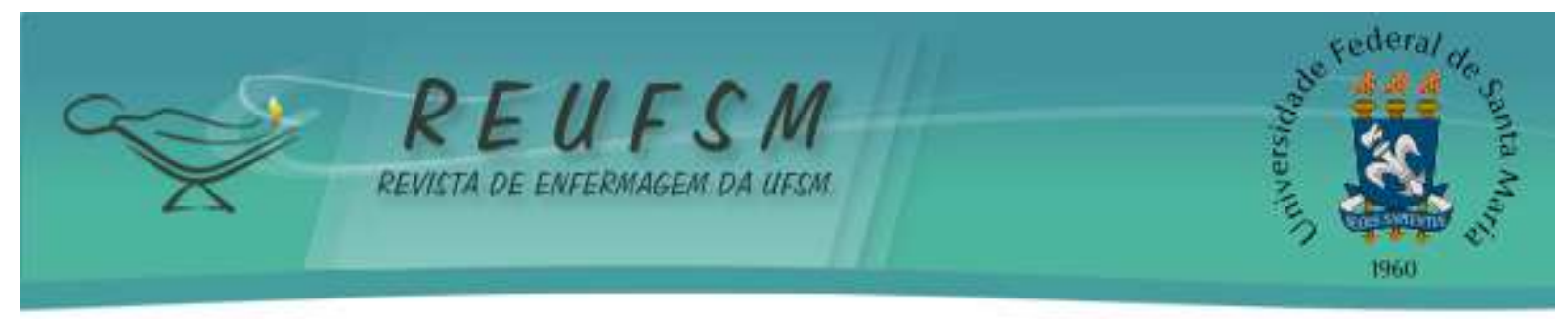

há necessidade de propor qual a intencionalidade do próprio texto em revelar as verdades do fenômeno. Portanto, a experiência se manifesta no sentido do discurso escrito, no qual se compreende a existência humana, desvelando a realidade em sua totalidade. ${ }^{11,22}$

A hermenêutica de Ricoeur compreende três fases: a leitura simples, a leitura crítica e a apropriação para compreender a existência humana, desvelando a realidade em sua totalidade pela experiência expressa no sentido do texto. Sendo assim, o fenômeno propõe ser desvelado a partir do momento em que o pesquisador compreende a intencionalidade do texto, ou seja, da vontade humana expressa na linguagem. ${ }^{10,20}$

Para a compreensão, o leitor necessita ir além do sentido literal das palavras na frase. Para tanto, a interpretação dos achados se estabeleceu texto por texto. Primeiramente, pela leitura simples buscou-se a aproximação da compreensão do texto, a partir das situações da realidade apreendidas do vivido do outro. Posteriormente, por meio da leitura crítica, os temas foram estruturados, tendo por base os segmentos do discurso escrito compreensivo no texto, os quais formaram uma unidade de sentido. ${ }^{9,20}$ Nessa etapa, foi utilizada a análise cromática para evidenciar a fundamentação teórico-filosófica de Merleau-Ponty.

A análise cromática surgiu como estratégia utilizada pelos pesquisadores a partir da ferramenta do word "cores de temas", a qual expressou a legenda de cores e significados. Assim, foi possível aproximar as unidades de sentidos expressas no texto e demarcadas por cores correlacionadas. Logo, houve a aproximação das unidades de significados (proposto pela hermenêutica de Ricoeur na leitura crítica), a partir das concepções do referencial filosófico Merleau-Pontyana, a citar: corpo, mundo, temporalidade, percepção, hábito, generalização, fala falante, fala falada, assim, por diante.

Após a terceira fase do referencial metodológico, a apropriação, a qual possibilitou compreender os sentidos e as imagens projetadas diante do texto ou, como lembra Ricoeur da metáfora que emergiu dos temas. A metáfora surge do conflito entre palavras e abarca uma nova significação na frase e revela algo novo diante da realidade e permite a compreensão do texto, a partir de um aprimoramento do sentido. ${ }^{9,22}$ Nesse estudo, a metáfora ${ }^{20}$ foi compreendida como Homem no mar, o qual reflete o ser humano que intenciona um mostrarse ou não, conforme as ondas do mar, em diferentes dimensões, na perspectiva do homem no mundo (homem e mulher). 


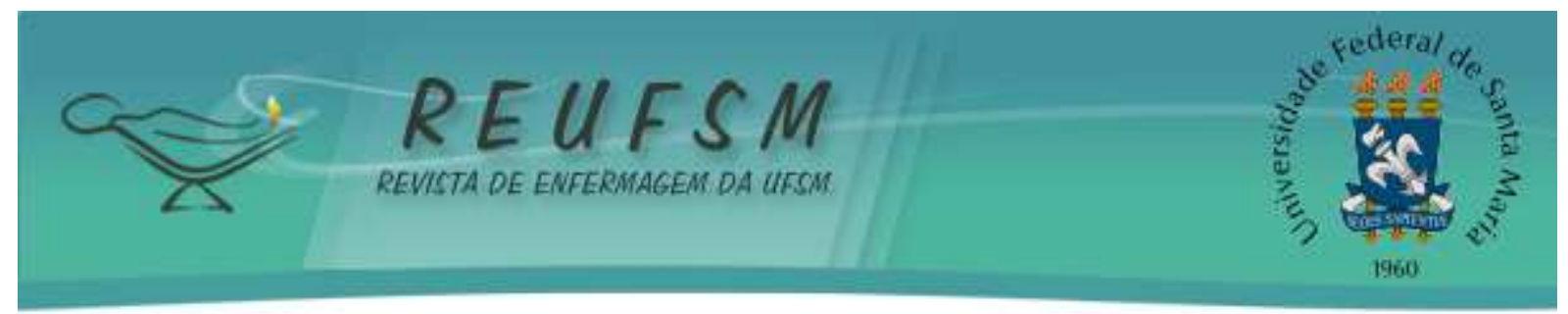

Este estudo seguiu os princípios da Resolução No 466/12 do Conselho Nacional de Saúde e foi aprovado pelo Comitê de Ética em Pesquisa com Seres Humanos da Universidade Federal de Santa Maria, sob o Parecer No 512.085/2014 em 14 de janeiro de 2014. Foi assegurado o princípio da autonomia do participante, que considera que o voluntário pode desistir a qualquer momento.

\section{RESULTADOS E DISCUSSÃO}

Intencionou-se convidar o leitor a explorar e a compreender o mundo do ser humano que vivencia o fenômeno, visto que desvela o diagnóstico e perspectivas do processo saúde-doença.

\section{O mundo do ser humano que vivencia a doença mental}

A percepção do ser humano diante do mundo, nesse momento, está imbricada na facticidade da existência humana numa rede de intencionalidades. Permeia a essência do ser humano, do vivido e seus significados na perspectiva de uma relação temporal, entre passado, presente e futuro. A temporalidade permeia um processo constituído subjetivamente, sendo a consciência a forma de todos os tempos. ${ }^{7-9} \mathrm{~A}$ consciência do momento repercute a anterioridade e a visão prospectiva, ou metaforicamente, como as ondas do mar no movimento da consciência do homem, perante os significados do seu vivido no mundo que habita.

O mundo expressa o lugar da experiência. Também, traduz o conjunto de horizontes sempre abertos que se busca conhecer e mostra os sentidos inacabados, pois existe sempre perspectivas que se modificam em direção ao novo e à facticidade. Além disso, presume a vivência como corpo fenomênico de relações subjetivas e intersubjetivas acontecem. Por isso, trata-se de retornar ao vivido (dos sentimentos), encontrando os fenômenos no estado nascente. ${ }^{8-11}$

Cada corpo se constitui de significados diante das vivências com o mundo, o qual é inacabado. É a consciência do ser humano enquanto existência encarnada, na qual tece experiências e do qual reflete, construindo a subjetividade. ${ }^{8-10}$ Contudo, o discurso do homem no mar aponta para a coletividade expressa na generalidade. ${ }^{8-11}$ Diante disso, por mais que há vivencias singulares, o corpo social reflete a doença mental, sendo o significado temporal desse mundo.

A condição do ser humano de se identificar com uma característica do outro, no sentido da generalização, propõe a concepção social e do próprio ser humano vivenciando a sua condição de doente mental, na percepção do preconceito. O resgate histórico da vida do 


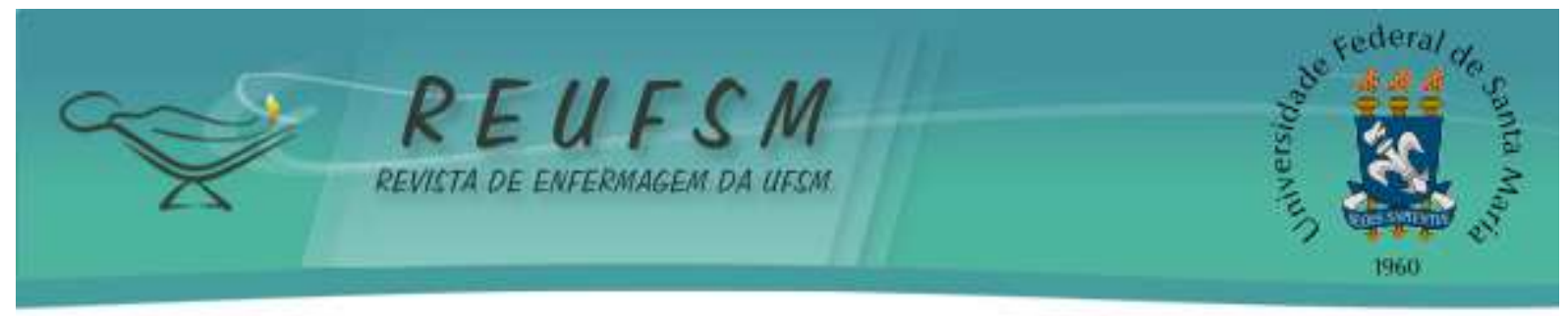

ser humano evidencia a descoberta do diagnóstico; as diversas formas de convivência com os sinais e sintomas demarcados em seu corpo; as formas de tratamentos, assim como as dificuldades e lutos diários na convivência cotidiana da doença mental.

Me surpreendi de certa forma [...] Nunca ouvi falar sobre isso [...] (fala arrastada) o dito bipolar. (H1)

Tu tem que aceitar que tu tem a doença, e pior é conviver com o preconceito: Aquele lá é louco. Olha só o jeito. (H2)

Eu tenho depressão. [baixa o tom de voz] eu acho ruim, a gente fica o tempo todo, querendo morrer, a gente tem um ataque de nervos [fica angustiada, e bebe muita água] tu querer morrer, tu querer se matar. Eu sinto muito, muito medo [se encolhe na cadeira] de morrer. (H9)

Contudo, cada ser humano escreve a história de vida a partir da essência, de concepções do seu mundo social e cultural. Logo, a singularidade permeia a condição de existência de si e no enfrentamento do fenômeno pesquisado. ${ }^{9-11}$ Nesse intuito, há o movimento da consciência de aproximar de si e de se relacionar com o mundo que deseja compreender.

Em contrapartida, o hábito se constitui nas amarras, molduras e máscaras que se expressam pela fala falada. Sobrepõe as cortinas em um movimento de sua liberdade, em movimento do seu mostrar-se como corpo próprio, pela fala falante. ${ }^{8-10} \mathrm{O}$ discurso do homem no mar ocorre, primeiramente, pela fala falada, pois o objetivo esperado pressupõe meramente o ato comunicativo de um interlocutor, o passo que se percebe, gradativamente, como corpo consciente no diálogo e no mundo do fenômeno interrogado. Assim, emerge a fala falante, na qual o discurso originário e criativo expressa os reais sentimentos e percepções diante do mundo vida, a fala falante. ${ }^{8-10}$

Nesse sentido, observa-se que pelo hábito e generalização o homem do mar emerge pela fala falada a sua condição diante de um diagnóstico e o poder enraizado pela história da loucura e o estereótipo do louco social, o que influencia diretamente no processo saúdedoença. Ao despertar o homem no mar pelo corpo próprio, percebe-se como um ser de singularidades e vivências únicas e refere pela fala falante a sua história de vida, a qual também permeia a existência de uma doença mental, mas não pode limitar sua condição de existência e suas relações com a família e a sociedade:

todo mundo não dá mais crédito para mim. (H3) 


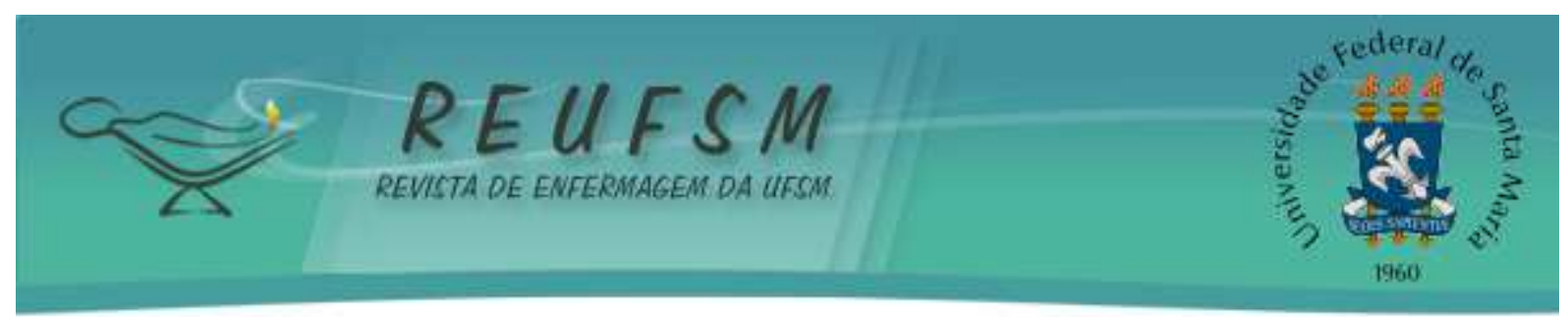

os dias que eu fiquei sem a minha cabeça, pensei que não iria voltar. Tu não vê a doença mental, tu sente isso. (H4)

a minha doença que me afasta deles [família]. Eles têm preconceito, me chamam de louca, é ruim ter preconceito [esfrega a mão contra as calcas a nível do joelho] um dia teus familiares vão se cansar de ti. (H5)

eu tenho a cabeça quebrada quando eu bato na minha mãe. Fico brabo [...] A gente toma remédio. Ele desce direitinho aqui [aponta para a garganta]. (H10)

Nesse ponto do mar, a indagação refere-se à veracidade de toda aventura no mundo vida. O ser humano apreende experiências, percepções, comportamentos e reconhece-se, gradativamente, como sendo ações no mundo, como consciência-encarnada. ${ }^{7-9}$ A consciência do corpo como seu próprio mundo refere à apropriação de significado do ser humano advindo de experiencia singulares e subjetivas, as quais incorpora esses significados à sua expressão.

Ao adentrar no mundo da doença mental por um diagnóstico e implicações sociais, há construções históricas de uma sociedade diante da loucura, que exclui o outro. Faz-se necessário desconstruir a ideia do objeto passivo sendo cuidado e incorporar aspectos humanos e sociais no processo saúde-doença, para efetivar o direito do cidadão frente à sua condição de saúde, o que pressupõe garantir acesso e efetividade terapêutica. ${ }^{1,24-25}$

Vislumbra-se compreender os aspectos de uma doença crônica no processo saúdedoença e propor ações de adaptações no cotidiano. Observa-se que há o desejo de cura; também, há relatos de esquiva ao tratamento pela não aceitação do próprio quadro clínico. também há menção de invadir o mundo do outro, do dependente de substância química:

se tivesse um remédio milagroso que curasse, mas não tem. Às vezes, ele te dá aparência de "louco, sabe"? (H6)

eu saí na rua correndo, e acharam que eu estava drogada. Eu disse não uso drogas! Eu estava toda "boletada". (H7)

a minha vida até agora foi maravilhosa. Tem altos e baixos, tem, isso aí todo mundo tem. Por que eu não vou ter? É uma coisa normal! Isso é a vida adaptada! Mas com certeza, eu queria a cura. (H8)

Para efetivar o cuidado em saúde mental pautado na política de humanização, a Rede Humaniza SUS norteia os dispositivos de uma linha de cuidado como a clínica ampliada, o apoio matricial, a intersetorialidade, o projeto terapêutico singular (PTS), a educação em saúde e a permanente. Essas estratégias em saúde mental são possibilitadas resguardadas as devidas proporções territoriais e da cobertura universal em saúde mental. ${ }^{6,24-25}$ 


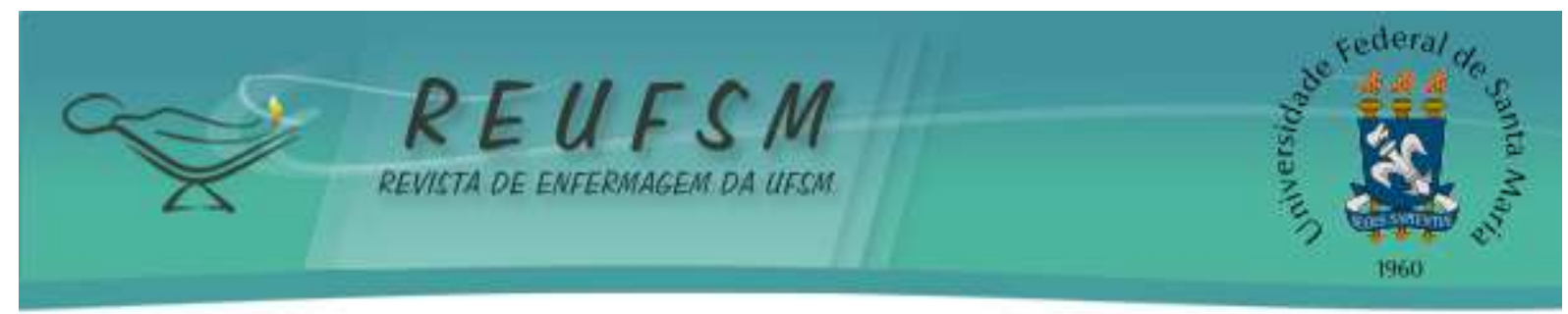

Há o mergulho no mundo da doença mental na perspectiva da clínica ampliada a fim de tecer, conjuntamente, as possibilidades terapêuticas e promover os projetos de vida. Para tanto, há que se criar estratégias para que o ser humano se empodere diante de propostas terapêuticas aconselhadas, buscando decisões compartilhadas entre profissionais de saúde, outros setores sociais, família e comunidade.

\section{CONSIDERAÇÕES FINAIS}

Ao desvelar a percepção do ser humano na descoberta do mundo da doença mental e as perspectivas no processo saúde-doença, os participantes desse estudo, metaforicamente como o homem ao mar, percebem a doença mental como o corpo vivido e expressam suas percepções a partir de suas vivências da fala falada e da fala falante. Assim, cada um tem seu tempo, que não é cronológico, mas de movimento, de significados para si diante do desejo de liberdade em um mundo inacabado.

Não há como negar o fato da existência da doença mental e algumas limitações diante do quadro clínico de situação crônica, o que desperta desafios no enfrentamento do processo saúde-doença. Também, observa-se a generalização enquanto doença mental. Contudo, o homem no mar, ao lançar da percepção de sua condição singular no mundo que vivencia uma doença mental, a qual requer adaptações no cotidiano e terapêuticas adequadas, assume a sua identidade enquanto responsabilidades em escolhas de vida e protagonismo nas negociações terapêuticas enfatizadas pelas políticas públicas.

Aos profissionais da saúde, recai o papel da educação em saúde e o cuidar pautado na integralidade. Para tanto, é necessário desvelar as reais necessidades do ser humano, na qual a fala falante é essencial para tecer redes de significações diante do processo saúde-doença e das perspectivas terapêuticas.

Como possível limitação do modelo teórico exposto, observa-se o recorte espacial e temporal específico de um serviço que assiste pessoas que vivenciam a doenças mental. Para agregar conhecimento no processo saúde-doença, sugere-se a produção de conhecimento em outros cenários da rede de saúde como, por exemplo, a estratégia Saúde da Família (ESF), O centro de Atenção Psicossocial (CAPS), bem como serviços de apoio como o Centro de Referência de Assistência Social (CRAS), coordenadorias de saúde, poder judiciário e outros segmentos da sociedade. 


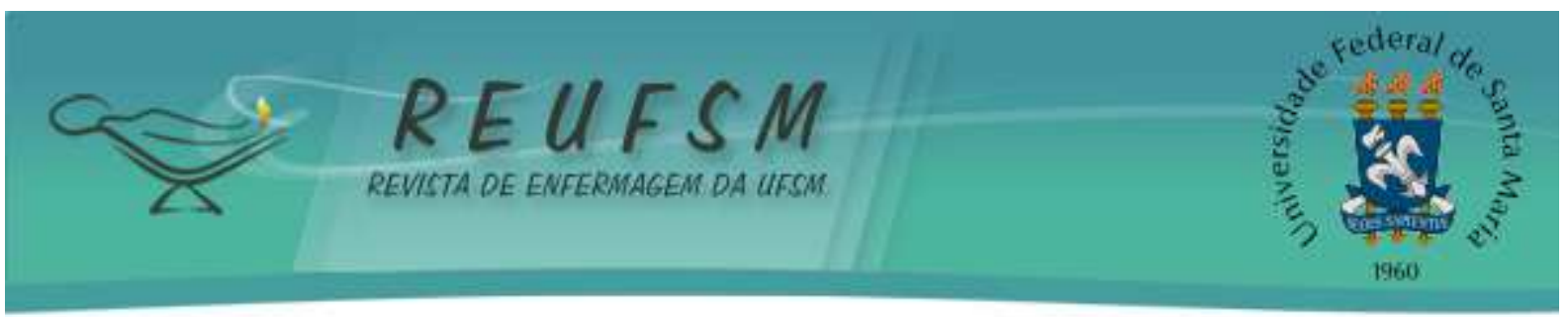

\section{REFERÊNCIAS}

1. Vasconcelos MGF, Jorge MSB, Catrib AMF, Bezerra IC, Franco TB. Projeto terapêutico em saúde mental: práticas e processos nas dimensões constituintes da atenção psicossocial. Interface Comun Saúde Educ [Internet]. 2016 [acesso em 2018 jul 16];20(57):313-23. Disponível em: https://www.scielosp.org/pdf/icse/2016.v20n57/313-323/pt.

2. Brasil. Lei $\mathrm{n}^{\circ} 10.216$, de 06 de abril de 2001. Dispõe sobre a proteção e os direitos das pessoas portadoras de transtornos mentais e redireciona o modelo assistencial em saúde mental. Diário Oficial, Brasilia; 2011 abr 09.

3. Wetzel C, Pinho LB, Olschowsky A, Guedes AC, Camatta MW, Schneider JF. A rede de atenção à saúde mental a partir da Estratégia Saúde da Família. Rev Gaúcha Enferm [Internet]. 2014 [acesso em2018 jul 16];35(2):27-32. Disponível em: http://www.scielo.br/pdf/rgenf/v35n2/pt_1983-1447-rgenf-35-02-00027.pdf.

4. Ely GZ, Terra MG, Silva AA, Freitas FF, Padoin SMM, Lara MP. Internação psiquiátrica: significados para usuários de um centro de atenção psicossocial. SMAD, Rev Eletrônica Saúde Mental Alcool Drog [Internet]. 2014 [acesso em2018 jul 16;10(1):23-8. Disponível em: http://www.revistas.usp.br/smad/article/view/86760.

5. Azevedo EB, Carvalho RN, Cordeiro RC, Costa LFP, Silva PMC, Filha MOF. Tecendo práticas intersetoriais em saúde mental para pessoas em sofrimento psíquico. Rev Enferm UFSM [Internet]. 2014 [acesso em 2018 jul 16;4(3):612-23. Disponível em: https://periodicos.ufsm.br/reufsm/article/view/13562/pdf.

6. Deschamps ALP, Rodrigues J. Política de saúde mental e projeto terapêutico singular. Cadernos Brasileiros de Saúde Mental [Internet]. 2016 [acesso em 2018 jul 16];8(17):78-92. Disponível em: http://stat.ijie.incubadora.ufsc.br/index.php/cbsm/article/view/3024/4427.

7. Merleau-Ponty M. A união da alma e do corpo. São Paulo: Autentica; 2016.

8. Merleau-Ponty M. O primado da percepção e suas consequências filosóficas. São Paulo: Autentica; 2015.

9. Silva AA, Terra MG, Motta MGC, Leite MT, Padoin SMM. Enfermagem e cuidado de si: percepção de si como corpo existencial no mundo. Rev Enferm UERJ [Internet]. 2013 [acesso em 2018 jul 17];21(3):66-70. Disponível em: http://www.epublicacoes.uerj.br/index.php/enfermagemuerj/article/view/7525/5445.

10. Freitas FF, Terra MG, Silva AA, Ely GZ, Girardon-Perlini NMO, Leite MT. Alta hospitalar da pessoa com transtorno mental: significados atribuídos pelo familiar. Rev Enferm UFPE [Internet]. 2013 [acesso em 2018 jul 17];7:6477-87. Disponível em: https://periodicos.ufpe.br/revistas/revistaenfermagem/article/viewFile/12295/14965.

11. Silva AA, Terra MG, Leite MT, Freitas FF de, Ely, GZ, Xavier MS. Enfermagem e cuidado de si no mundo do cuidado em psiquiatria. Rev Pesqui Cuid Fundam [Internet]. 2015 [acesso em 2018 jul 17];7(1):2011-20. Disponível em: http://www.redalyc.org/pdf/5057/505750945023.pdf.

12. Kantorski LP, Jardim VMR, Treichel CAS, Mola CL, Alves PF, Ferreira Z, et al. Fatores associados a uma pior avaliação da qualidade de vida entre familiares cuidadores de usuários de Centros de Atenção Psicossocial. Cad Saúde Colet [Internet]. 2017 [acesso em 2018 jul 


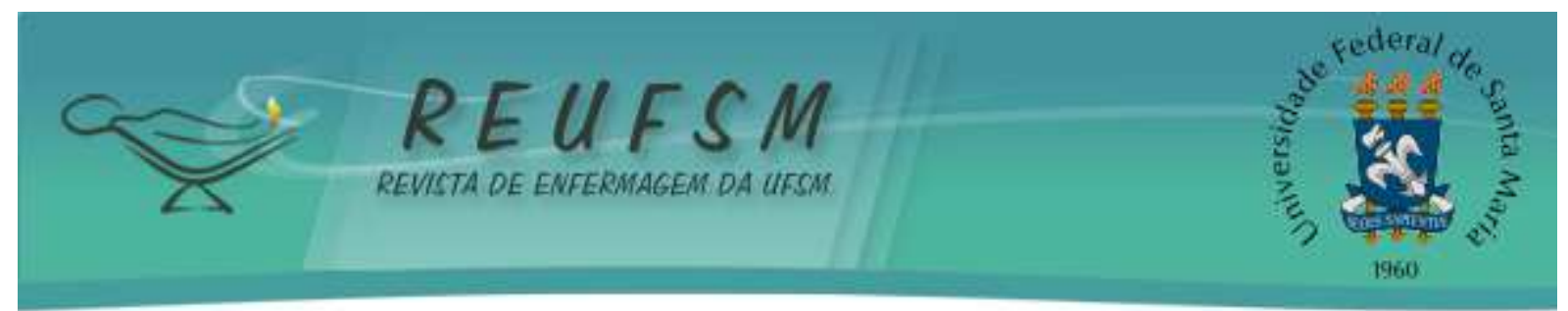

17];25(4):460-7. Disponível em: http://www.scielo.br/pdf/cadsc/v25n4/1414-462X-cadsc-254-460.pdf.

13. Dutra VFD, Bossato H, Oliveira RMP. Mediar a autonomia: um cuidado essencial em saúde mental. Esc Anna Nery [Internet]. 2017 [acesso em 2018 jul 17];21(3):e20160284. Disponível em: http://www.scielo.br/pdf/ean/v21n3/pt_1414-8145-ean-2177-9465-EAN2016-0284.pdf.

14. Cardoso MRO, Oliveira PTR, Piani PPF. Práticas de cuidado em saúde mental na voz dos usuários de um Centro de Atenção Psicossocial do estado do Pará. Saúde Debate [Internet]. 2016 [acesso em 2018 jul 17];40(109):86-99. Disponível em: http://www.scielo.br/pdf/sdeb/v40n109/0103-1104-sdeb-40-109-00086.pdf.

15. Reisdorfer N, Araújo GM, Hildebrandt LM, Gewehr TR, Nardino J, Leite MT. Suicídio na voz de profissionais de enfermagem e estratégias de intervenção diante do comportamento suicida. Rev Enferm UFSM [Internet]. 2015 [acesso em 2018 jul 17];5(2):295-304. Disponível em: https://periodicos.ufsm.br/reufsm/article/view/16790/pdf.

16. Pinho LB, Kantorski LP, Olschowsky A, Schneider JF, Lacchini AJB. Ideologia e saúde mental: análise do discurso do trabalhador no campo psicossocial. Texto \& Contexto Enferm [Internet]. 2014 [acesso em 2018 jul 17];23(1):65-73. Disponível em: http://www.scielo.br/pdf/tce/v23n1/pt_0104-0707-tce-23-01-00065.pdf.

17. Sedláčková Z, Kamarádová D, Praško J, Látalová K, Ocisková M, Cinculová A, et al. Treatment adherence and self-stigma in patients with depressive disorder in remission - A cross-sectional study. Neuroendocrinol Lett [Internet]. 2015 [acesso em 2018 jul 17];36(2):171-7. Disponível em: https://pdfs.semanticscholar.org/0479/41ad852c7248b7a7a3836a580e8554abb560.pdf.

18. Holubova M, Prasko J, Latalova K, Ociskova M, Grambal, Kamaradova AD, et al . Are self-stigma, quality of life, and clinical data interrelated in schizophrenia spectrum patients? A cross-sectional outpatient study. Dovepress [Internet]. 2016 [acesso em 2018 jul 17];10:26574. Disponível em: https://www.dovepress.com/are-self-stigma-quality-of-life-and-clinicaldata-interrelated-in-schi-peer-reviewed-article-PPA.

19. Seed T, Fox JRE, Berry K. The experience of involuntary detention in acute psychiatric care. A review and synthesis of qualitative studies. Inter J Nurs Studies [Internet]. 2016 [acesso em 2018 jul 17];61:82-94. Disponível em: http://www.journalofnursingstudies.com/article/S0020-7489(16)300633/fulltext.

20. Daniel Frey D, Stricke N, organizadores. Escritos e conferências de Paul Ricoeur (2 Hermenêutica)-. São Paulo: Loyola; 2017.

21. Guerrero-Castaneda RF, Menezes TMO, Ojeda-Vargas MG. Características da entrevista fenomenológica na pesquisa em enfermagem. Rev Gaúcha Enferm [Internet]. 2017 [acesso em 2018 jul 17];38(2):e67458. Disponivel em: http://www.scielo.br/pdf/rgenf/v38n2/01026933-rgenf-1983-144720170267458.pdf.

22. Oliveira PP, Viegas SMF, Santos WJ, Silveira EAA, Elias SC. Mulheres vítimas de violência doméstica: uma abordagem fenomenológica. Texto \& Contexto Enferm [Internet]. 2015 [acesso em 2018 jul 17];24(1):196-203. Disponível em: http://www.scielo.br/pdf/tce/v24n1/pt_0104-0707-tce-24-01-00196.pdf. 


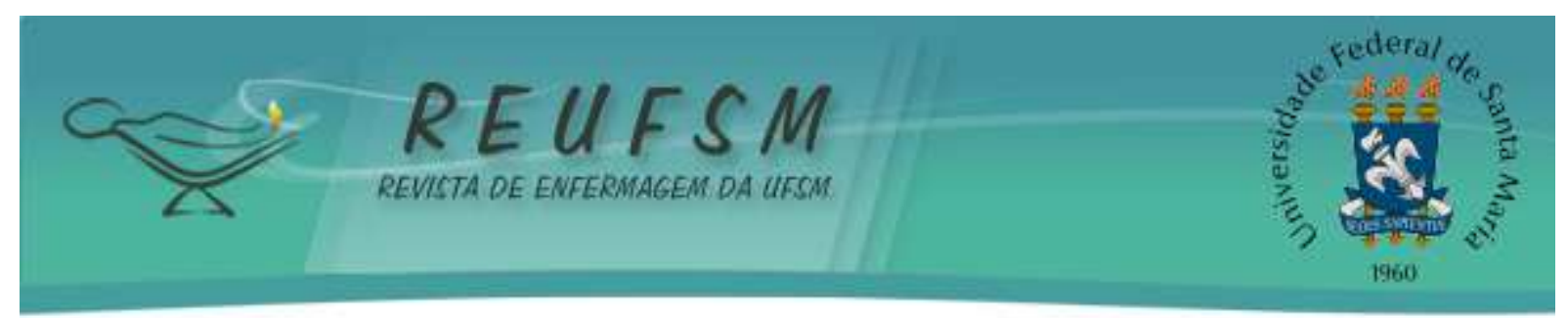

23. Braga R. 200 crônicas escolhidas. Rio de Janeiro: Record; 2018.

24. Figueredo WN, Rios DRS, Teles PSF, Magalhães TKSB, Véras, RM Permanecer SUS: a (re) formação em saúde sob a perspectiva do acolhimento e da humanização. Rev Enferm UFSM [Internet]. 2015 [acesso em 2018 jul 17];5(3):465-75. Disponível em: https://periodicos.ufsm.br/reufsm/article/view/13593/pdf.

25. Ferreira TPS, Sampaio J, Souza ACN, Oliveira DL, Gomes LB. Produção do cuidado em saúde mental: desafios para além dos muros institucionais. Interface [Internet]. 2017 [acesso em 2018 jul 17];21(61):373-84. Disponível em: http://www.scielo.br/pdf/icse/v21n61/18075762-icse-1807-576220160139.pdf.

Data de submissão: 27/05/2017

Data de aceite: 19/07/2018

Autor correspondente: Gabriela Zenatti Ely

E-mail: gabii_ely@yahoo.com.br

Endereço: Rua Vale Machado 1605, Ap 106. Santa Maria - RS

CEP: 97010530 